\title{
COMO CONSTRUIR CIDADES SUSTENTÁVEIS?
}

\author{
Mônica Michelotti Loureiro ${ }^{1}$ \\ Isabel Christine Silva De Gregori ${ }^{2}$
}

\section{RESUMO}

Alcançar para as Cidades o patamar de sustentáveis, é uma pretensão necessária, já que, atualmente, são evidentes as consequências do desenvolvimento desenfreado e irresponsável. A abordagem da questão ambiental urbana está entre os temas de maior relevância no mundo atual, devido ao crescimento demasiado das cidades e à ausência de estruturas sustentáveis capazes de manter ambientes equilibrados nos espaços urbanos. Propõem-se, ações conjuntas tanto da administração, como dos grupos sociais, na busca de um ambiente urbano sustentável. A metodologia utilizada para realização do trabalho foi revisão bibliográfica, onde se almeja destacar a sustentabilidade como forma de prevenção do meio ambiente, assim como, a importância de ações sustentáveis como fonte de promoção de cidadania. Por fim, há uma gama de atitudes, que podem melhorar a qualidade de vida dos cidadãos de forma equitativa.

Palavras-chave: Direito Urbanístico e Ambiental, desenvolvimento das cidades, crescimento Urbano Sustentável.

\section{CONSIDERAÇÕES INTRODUTÓRIAS}

Este artigo tem como objetivo a análise do Direito Urbanístico Ambiental, enfatizando acerca de como podemos construir cidades sustentáveis. Devemos considerar aspectos de suma importância para que ocorram transformações, tratam-se das necessidades que se fazem presente no cotidiano da sociedade. Conforme explicita Henrique Rattner:

No limiar do século XXI, quase todas as sociedades enfrentam a desanimadora perspectivas de uma infindável crise urbana, consequência de um modelo obsoleto e irracional da ocupação do espaço. Ademais, a acumulação de riquezas sem distribuição equitativa de benefícios sociais exacerbou contradições e conflitos, particularmente nas grandes aglomerações urbanas (...). ( 2001, p. 9).

\footnotetext{
${ }^{1}$ Autora e Acadêmica do $6^{\circ}$ semestre do Curso de Direito da Universidade Federal de Santa MariaUFSM. Integrante do Grupo de Pesquisa Direito da Sociobiodiversidade da UFSM E-mail: monicaml24@gmail.com

${ }^{2}$ Co-Autora e Orientadora. Doutora em Desenvolvimento regional pela Univeridade de Santa Cruz do Sul - UNISC (2007), mestre em Integração Latino-Americana pela Universidade Federal de Santa Maria UFSM (1999). Graduada em Direito pela Universidade Federal de Santa Maria- UFSM (1985).

Atualmente é professora adjunta do Departamento de Direito da Universidade Federal de Santa Maria, chefe de departamento substituta e coordenadora do Núcleo de Pesquisa e Extensão do Curso de Direito. Atua junto a Pró-reitoria dePós-Graduação e Pesquisa da UFSM, como membro integrante do Comite de Ética em Pesquisa - CEP. Tem experiência na área de Direito Privado, com ênfase nas disciplinas de Direito Civil e Empresaria. Ministra as disciplinas de Direito Empresarial, Estudos Interdisciplinares A, Estudos Intedisciplinares B , Monografia Juridica I e II e Direito Ambiental. Exerce a docência desde 1994.
} 
A humanidade está em um patamar de desenvolvimento tecnológico e social que causaram danos gravíssimos para a natureza. Deste modo, afetou diretamente fatores vitais para o ser humano, uma vez que a poluição cresceu juntamente com o desenvolvimento das sociedades. A grande quantidade de veículos nas ruas, nos últimos anos, fez aumentar os índices de gases nocivos à saúde na atmosfera. O lixo jogado nas ruas causa entupimento de bueiros, o que dificulta o escoamento da água da chuva. Além disso, mesmo quando ocorre o escoamento, a água leva detritos diretamente para o curso dos rios, córregos, mananciais, entre outros. Sendo assim, um meio indireto, mas eficiente de se poluir a água. O aumento das cidades e de lavouras no campo de forma irresponsável contribui maciçamente com o desmatamento. De acordo com Henrique Rattner: “(...) A urbanização rápida e a intensa concentração de indústrias, serviços e, portanto, de seres humanos, têm transformado as cidades no oposto de sua razão de ser (...)" (Op. cit., p. 9).

Ocorreu a iniciativa de se buscar novos métodos para conciliar desenvolvimento social e tecnológico com a conservação dos recursos naturais. A sustentabilidade veio para fazer a referida conciliação de modo que ao mesmo tempo em que o ser humano produza desenvolvimento, também conserve a natureza. A sustentabilidade implica mudanças, novos pontos de visto e novas políticas públicas de como agir cotidianamente no local que vivemos.

Desenvolvimento sustentável é um conceito que quase todas as pessoas já escutaram, contudo, só o conhecem de maneira abstrata. Muitas dessas pessoas têm a ideia que medidas sustentáveis são transformações ínfimas, lentas e em longo prazo; e ainda, que somente ocorreriam em nível global, guiadas por organismos internacionais e ONGs. Essa pré compressão do cidadão urbano comum sobre a proteção do meio ambiente a qual ocorre em nível mundial, um palco de planos de implementação em macrosistemas, não é suficiente, apesar da grande importância dessa consciência em nível internacional.

Contudo, devido à importância e rapidez com que alterações na forma de agir devem ser tomadas para preservar a vida das gerações futuras, escolhemos nesse artigo restringir o apanhado sobre sustentabilidade nas cidades (microssistemas), para assim, aproximar o desenvolvimento sustentável da realidade cotidiana dos moradores urbanos, analisando esse tema a luz do direito Ambiental Urbanístico. 

III SEMINÁRII ECDLOGIA

POLÍTICA

entendimento sobre o próprio desenvolvimento, idealizado agora como um desenvolvimento urbano sustentável.

Após analisar a evolução histórica das cidades evidencia-se que está influenciou diretamente a criação de legislação jurídica a fim de melhor organizá-las, assim como para proteger o meio ambiente urbano visando um ambiente sadio para a população que vive nas cidades.

De fato, a ocupação e o desenvolvimento dos espaços abitáveis sejam eles no campo ou na cidade, não podem ocorrer de forma meramente acidental, sob as forças dos interessas privados e da coletividade. Ao contrário, são necessários profundos estudos acerca dos estudos da ocupação, sua finalidade, avalição da geografia local, da capacidade de comportar essa ocupação sem danos para o meio ambiente, de forma a permitir boas condições de vida para as pessoas, permitindo desenvolvimento econômico-social, harmonizando os interesses particulares e da coletividade.

A Constituição Federal de 1988 pôs fim a todas as controvérsias: além de reconhecer explicitamente o Direito Urbanístico e o Direito Ambiental como ramos autônomos, distribui competências legislativas em matérias urbanísticas e ambientais enfatizando a ação municipal, e também, define o princípio da função social da propriedade. (Ob. cit., p. 21).

Foi tendo em vista essa necessidade de planejar os ambientes urbanos que a Carta Magna, como primórdio na legislação brasileira, trouxe regras de direito urbanístico, ou seja, regras para direcionar as relações sociais na cidade. Ela contém um capítulo sobre Política Urbana, na qual previu o principio da função social da cidade, a fim de, garantir o bem estar dos seus habitantes. Assim, prevê o art. 182 desse capítulo:

CF, Art. 182. A política de desenvolvimento urbano, executada pelo Poder Público municipal, conforme diretrizes gerais fixadas em lei, tem por objetivo ordenar o pleno desenvolvimento das funções sociais da cidade e garantir o bem- estar de seus habitantes.

Esse dispositivo prevê como objetivo da política de desenvolvimento urbano promover o desenvolvimento das funções sociais da cidade para garantir o bem estar de seus cidadãos. Objetivo o qual só poderá ser atingido com a valorização da função ambiental do meio urbano. Esse capítulo da Constituição não previu explicitamente uma inter-relação da função social com a ambiental no meio urbano (previsão de cidades sustentáveis), então, anos após foi promulgado o instrumento legislativo que considerou 
III SEMINÁRII ECDLOGIA

POLÍTICA

Atualmente se constata que os problemas enfrentados por moradores das cidades se intensificaram. Alguns autores opinam que vivemos em um tempo de crise das cidades (BARAT, 2012). Nesse momento histórico, esse quadro decorre geralmente da alta concentração populacional nas cidades e ausência de planejamento sustentável nos momentos de criação e desenvolvimento das mesmas, ou seja, carência em manter um ambiente urbano transformando-se a todo instante sustentavelmente.

Nas linhas seguintes buscaremos relacionar de forma harmônica a aparente antinomia entre o desenvolvimento acelerado das cidades e a busca por ambientes urbanos sustentáveis, visto que, somente um pensamento progressista quanto a esses conceitos poderá conter essa "crise urbana".

O modelo de "cidade sustentável", surgido no âmbito dos organismos internacionais, é a extensão, para a esfera local, da operacionalização da noção de desenvolvimento sustentável, concebido como aquele que assegura o atendimento das necessidades do presente sem comprometer as necessidades das gerações futuras satisfazerem também as suas. (ACSELRAD, 2001, p. 105-106).

A perda da biodiversidade, mudanças climáticas ou a destruição da camada de ozônio foram consequências de anos de desenvolvimento econômico sem nenhuma preocupação com as questões ambientais. Contudo, ao aparecer esse novo quadro climático, quase todos os ramos da sociedade passaram a pensar em medidas sustentáveis para o meio ambiente, a fim de tentar preservar a qualidade de vida dos povos.

Como entende José Chacon de Assis, novos enfoques na sociedade atual vêm resultando uma aproximação criativa entre o pensamento ecológico, a economia política e os estudos urbanos. (ASSIS, 2001, p. 8). Essa aproximação ao administrar as cidades é tão necessária que o planejamento urbano e a sustentabilidade ambiental estão assegurados pelo Plano Diretor das cidades.

Diversas iniciativas podem criar no ambiente urbano um lugar sustentável, o que é imprescindível para que não seja ameaçada a estabilidade das cidades ao longo dos anos. A ideia que deve guiar essas ações é que a sustentabilidade é um fator de desenvolvimento, e não um entrave a ele. E ainda tão importante como ser um fator de desenvolvimento, é que pode ser um fator de crescimento na renda das famílias mais necessitadas e de implementação de politicas sociais. 
Um exemplo é a separação de resíduos e reciclagem, que se realizada nos municípios, diminuiria muito a quantidade de lixo que se destina, ou para aterros sanitários ou para lixões a céu aberto. Ademais, a reciclagem produziria renda para muitas pessoas ao ser fonte de trabalho. Logo, é um exemplo de política urbana sustentável, a qual se implementada, traria benefícios ambientais e sociais.

Conforme destaca Henri Acselrad, o desafio da construção de cidades, com novos parâmetros, não se pode restringir as concepções de um urbanismo ecologizado que se satisfaça em promover cidades compactas, capazes de economizar espaço e energia, nem tampouco que tenha na sustentabilidade um mero atributo simbólico adicional para a competição interurbana desenvolvida através do marketing das cidades. Trata-se, isto sim, de pensar um novo modelo de desenvolvimento urbano, baseado nos princípios da democratização dos territórios, no combate à segregação socioespacial, na defesa dos direitos de acesso aos serviços urbanos e na superação da desigualdade social manifesta também nas condições de exposição aos riscos urbanos. (ACSELRAD, 2001, p. 23).

Dir-se-ão, sustentáveis as praticas que se pretendem compatíveis com a qualidade futura postulada como desejável, ou seja, é sustentável hoje aquele conjunto de práticas portadoras de sustentabilidade no futuro. (Ob. cit., p. 29-30).

Exemplos de ações visando à conservação e a proteção de meio ambiente, e a implementação de diretrizes para ambientes sustentáveis a serem implementadas nas cidades, ou por seus órgãos administradores ou pelos moradores urbanos, são: 1) Reestruturação e recolocação das indústrias com base em políticas enérgicas administrativas; 2) Ampliação das áreas verdes; 3) Despoluição dos rios; 4) Coleta Seletiva de Lixo; 5) Redução da poluição do ar; 6) Construção de ciclovias; e 7) Priorização do Transporte Público Municipal.

A concepção de sustentabilidade como trajetória progressiva rumo à eficiência eco-energética é normalmente acompanhada da constituição de uma base social de apoio a projetos de mudança técnica urbana, pela via da "educação ambiental", da disseminação de uma "consciência ecológica", de projetos comunitários de reciclagem ou pelo engendramento de uma "política de reciclagem". (Ob. cit., p.40). É imprescindível que a comunidade recebe possibilidades de agir diferente com atitudes atinentes a um melhor aproveitamento dos recursos e constante preocupação com a 
proteção do ambiente urbano. Portanto, a educação ambiental deve ser uma guia à sustentabilidade a se seguir pelos municípios.

A materialidade das cidades e as modalidades de sua reprodução são vistas também como dependentes das condições que legitimam seus pressupostos políticos. (Ob. cit., p.45). Como destaca Godard, a insustentabilidade exprime, assim, a incapacidade de as políticas urbanas adaptarem a oferta de serviços urbanos à quantidade e à qualidade das demandas sociais qualidade, provocando um "desequilíbrio" entre necessidades cotidianas da população e os meios de as satisfazer, entre a demanda por serviços urbanos e os investimentos em redes e infraestrutura.(Ob. cit., p.40-45).

Atitudes concretas dos governos dos Municípios são fundamentais para que as cidades sejam sustentáveis, tanto como fatores diretos de sustentabilidade como para uma paulatina educação ambiental dos cidadãos. Nessa perspectiva, o direito deve estar impregnado de previsões, afim de, tornar as cidades sustentáveis. No âmbito da legislação, a cidade de São Paulo avançou positivamente nesse aspecto, ao sancionar a Lei das Ciclovias, em 2007, com o objetivo de desenvolver a mobilidade sustentável. Ela obriga centros de compras e outros locais com grande fluxo de pessoas a oferecer estacionamento de bicicletas como parte da infra-estrutura, prevê um sistema cicloviario para a cidade, além de outras medidas.(BRASIL. Lei ${ }^{\circ}$. 14.266, 2007).

\section{JUSTIÇA AMBIENTAL: COMO RESISTIR À AMPLIAÇÃO DO RISCO SOCIAL}

A questão ambiental sofreu uma ressignificação ao longo dos anos. Far-se-á uma linha de análise dos significados que lhe foram atribuídos nós últimos anos. Desde o início, a discussão da questão ambiental moveu-se entre dois pólos, ora contracultural, ora utilitário. O primeiro constitui um movimento que questiona o estilo de vida do consumismo fordista. ${ }^{3}$ O segundo, hegemônico, é um sentido utilitário preocupado em assegurar a continuidade da acumulação do capital.

\footnotetext{
${ }^{3}$ Fordismo é o nome atribuído à combinação de normas de produção, normas de consumo e instituições reguladoras que asseguraram o crescimento prolongado das economias ocidentais nos trinta anos seguintes a II Guerra Mundial. A produção e o consumo de massas, juntamente com a elevada intensidade de uso de energia fóssil, estão entre suas características básicas.
} 
O meio ambiente do ponto de análise da razão utilitária é único e composto estritamente de recursos materiais, sem nenhum vínculo com a realidade sociocultural. Esse ponto de vista, justifica interrogações sobres os meios e não sobre os fins para os quais a sociedade se apropria dos recursos do planeta; pressupõe um risco ambiental único, instrumental, ou seja o risco de inviabilização crescente da cidade produtiva, por poluição, congestionamento etc. Dado esse ambiente único, objeto instrumental da acumulação de riqueza, a poluição é apresentada como "democrática", não propensa a fazer distinções de classe. (ACSELRAD, 2005, p. 220).

Já a razão cultural se preocupa com os fins pelos quais os homens se apropriam dos recursos do planeta. Aqui, os riscos ambientais são distintos para cada pessoa dependendo do grupo social que se inclui, devido à possibilidade de alguns de se distanciarem desses ricos. Em meio a essa desigualdade ambiental, os que menos usufruem dos "benefícios do desenvolvimento" são, em contra partida, os mais afetados pela exposição aos riscos ambientais, consequência, em muitos casos, as redes técnicoprodutivas da riqueza. Segundo Henri Acselrad (2005, p. 221), “A poluição não é, nesta perspectiva, necessariamente "democrática", podendo afetar de forma variável os diferentes grupos sociais".

Portanto, a falta de iniciativa no que tange a proteção do meio ambiente também é um fator de desigualdade social, tendo em vista que, os moradores, marginalizados socialmente, geralmente, estão expostos diariamente a um maior nível de poluição. Os referidos moradores são mais vulneráveis por habitarem em locais mais desprotegidos em que as consequências da não preservação do meio ambiente, muitas vezes, causam consequências devastadoras para muitas famílias.

Assim, as duas razões correspondem a dois modelos de ação estratégica. A primeira, utilitarista, somente comprometida com as classes potencialmente consumidoras e com o desenvolvimento econômico exacerbado, ou seja, uma visão totalmente ultrapassada por estar em desacordo com os valores traçados pela Carta Magna Brasileira de 1988. No entanto, a razão cultural condiz com a defesa da justiça ambiental. Ao diagnosticar o "conflito ambiental", em que os mais ricos conseguem escapar aos riscos ambientais e os mais pobres estão constantemente expostos a esse quadro preocupante, e planejar ações visando combater a desigualdade ambiental, ao dar proteção ambiental a todos os grupos sociais. 
III SEMINÁRII ECDLOGIA

POLÍTICA

Portanto, a defesa de um meio ambiente urbano sustentável possui vinculação direta com as condições de produção e reprodução da sociedade naquele espaço. Logo, a justiça ambiental através dos movimentos sociais podem produzir mudanças no aparelho estatal e regulatório responsável pela proteção ambiental, pois esses grupos ao defender à igualdade de alcance aos recursos ambientais valorizam as culturas tradicionais opostas às técnicas industrializadas que não guardam nenhuma preocupação com a proteção ambiental. Assim, através de estratégias argumentativas e lutas inovadoras esses grupos sociais auxiliam em transformar o ambiente em um espaço efetivação da justiça e não de segregação social, como fazem os defensores da razão utilitária do mercado.

\section{CONSIDERAÇÕES FINAIS}

O número de cidades aumentou muito nos últimos anos, assim como, o numero de habitantes vivendo nelas. Situação que provocou diversas mudanças ambientais, estruturais e na maneira de pensá-las. Esse crescimento foi tão intenso e acelerado que não guardou proporções com o planejamento realizado nos ambientes urbanos nesses anos. Como consequência do mau planejamento e desenvolvimento industrial acelerado, surgiram diversos problemas, alguns, verdadeiras catástrofes, prejudicando a vida de diversas pessoas.

Percebeu-se, então, que esse desenvolvimento urbano devia regrar-se através de leis almejando um desenvolvimento urbano voltado ao bem comum. Para isso, o passo precursor foi dado pela Constituição Federal de 1988 que reconheceu o direito Urbanístico e o Direito Ambiental como autônomos; e previu outras medidas, afim de, direcionar as relações sociais na cidade visando a construção de um ambiente saudável à sua população.

Contudo, não é possível pensar-se em uma cidade saudável sem a conectar simultaneamente com políticas de proteção ao meio ambiente. Por isso, em 2001 se promulgou o Estatuto da cidade, que retomou preceitos constitucionais, mas acrescentou como objetivo primordial dessa legislação a garantia de um ambiente sustentável e sadio nas cidades, ou seja, acrescentou a importante relação do desenvolvimento sustentável no ambiente urbano. 
A defesa do meio ambiente deve ser vista como uma ação conjunta de diversos grupos sociais, deixando de lado a ideia ultrapassada de que os "únicos" responsáveis seriam os governantes. Pois, com o nível de desenvolvimento tecnológico alcançado nas cidades e a excessiva degradação dos recursos naturais tornou-se imprescindível, para evitar a ruina das mesmas, considerar a tentativa de construir ambientes sustentáveis uma obrigação de todos os cidadãos.

Tal obrigação, além de, quando concretizada ser promotora de cidadania, ao almejar o alcance do bem comum, evita que a vida das pessoas marginalizadas nos ambientes urbanos se torne, cada vez, mais precária, ao estarem constantemente expostas a diversos riscos ambientais e consequências desagradáveis da grande poluição dos ambientes urbanos. Necessita-se da mobilização de todos os segmentos da sociedade brasileira na busca de soluções para as questões para as questões ambientais, porque, assim, além da promoção de uma melhor qualidade de vida a todos, se evitará que os mais necessitados economicamente sejam prejudicados pelos desastres ambientais, já que não possuem as proteções que estão ao alcance das classes sociais mais abastadas.

É necessário, portanto, despertar novas percepções acerca de que cidades estão sendo construídas, que valores estão sendo postos em destaque em nossos ambientes urbanos como norte a se seguir. Essas reflexões são essenciais para priorizar atitudes em defesa da sustentabilidade e não simplesmente implantar táticas de mercado sem nenhuma preocupação com o futuro das nossas cidades. Portanto, evidencia-se que muitas políticas públicas são paliativas ao não eleger a defesa de um ambiente saudável como fundamental a todas as outras práticas de desenvolvimento, contudo, as medidas em defesa a um ambiente sustentável possuíam características totalmente opostas a essas citadas precedentemente, sendo uma visão que se posta em prática transforma a vida das pessoas social e sadiamente.

\section{REFERENCIAS BIBLIOGRÁFICAS}

ACSELRAD, Henri. A duração das cidades - Sustentabilidade e risco nas Políticas Urbanas. Ed. PB\&A. 2001. 


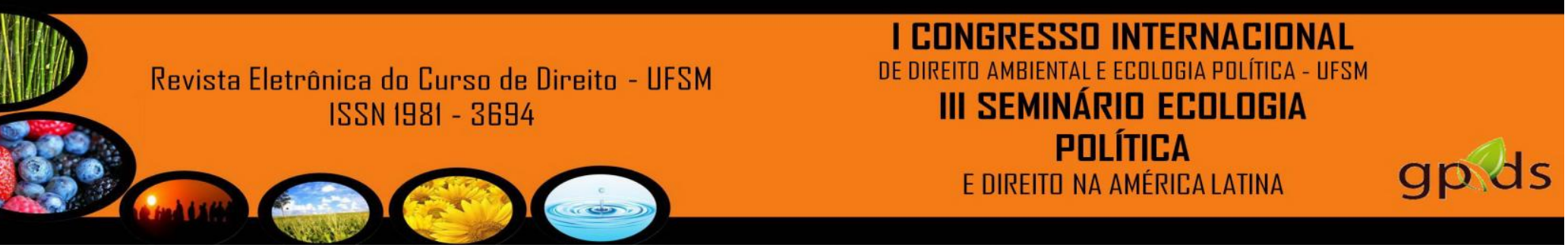

ACSELRAD, Henri. Justiça Ambiental: Narrativas de resistência ao risco social ampliado. In: MINISTÉRIO DO MEIO AMBIENTE, SECRETARIA EXECUTIVA, DIRETORIA DE EDUCAÇÃO AMBIENTAL. Encontros e Caminhos: Formação de educadoras(res) ambientais e coletivos educadores. 2005. Cap. 18, p. 219-228.

ARAIA, Eduardo. O caso Tâmisa. Disponível em: $<$ http://mosalsaneamentodescentralizado-mosal.blogspot.com.br/2012/06/politicas-publicas-residuossolidos-e.html>. Acesso em: 24 ago. 2012.

ASSIS, José Chacon de. Apresentação do livro A duração das Cidades Sustentabilidade e risco nas Políticas Urbanas de Henri Acselrad. Ed. PB\&A. 2001.

BARAT, Josef. Crise Urbana-O maior. $<$ http://bgcoaching.wordpress.com/2005/11/16/crise-urbana-o-desafio-maior-por-josefbarat/>. Acesso em: 24 Ago. 2012.

BRASIL. Constituição (1988). Constituição da República Federativa do Brasil. Brasília, DF, Senado,1998.

BRASIL. Lei $\mathbf{n}^{0}$ 14.266, de 6 de Fevereiro de 2007.

BRUNDTLAND, Relatório. Processo Preparatório da Conferência das Nações Unidas sobre Meio Ambiente e Desenvolvimento. 1987 apud ACSELRAD, Henri. A duração das cidades - Sustentabilidade e risco nas Políticas Urbanas. Ed. PB\&A. 2001.

FERNANDES, Edésio. Direito Urbanístico e Política Urbana no Brasil: Uma introdução. In: .Direito Urbanístico e Política Urbana no Brasil. Ed. Del Rey. 2001. Cap. 1, p. 11-52.

GODARD, O. Environnemen, Modes de Coordination et Sistèmes de Legimité: Analyse de la Categorie de Patrimoine Naturel. Révue Economique. n. 2, Paris, mar. 1990.

RATTNER, Henrique. Prefácio do livro A duração das Cidades - Sustentabilidade e risco nas políticas Urbanas de Henri Acselrad. Ed. PB\&A. 2001. P.9.

SARNO, Daniela Campos Libórnio Di. Elementos de Direito Urbanístico. $1^{\mathrm{a}}$ ed. 2004. 